\title{
The UAV Technology as a Future-Oriented Direction in the Development of Low-Ceiling Aerial Photogrammetry**
}

\section{Introduction}

The goal of this paper is to provide a review of the current state of knowledge concerning the tendencies in the development of unmanned aerial vehicles (UAVs), as regards to photogrammetric projects.

It has for long been known that photogrammetry is the quickest method for the acquisition of spatial data for larger areas. Also known are the limitations of photogrammetry. One of them is weather, and the other is the cost of a photogrammetric record flight. An hour of such flight constitutes a considerable part of relevant project costs, since they have to include the depreciation of an expensive equipment (cameras, scanners, GPS/INS devices), crew remuneration, fuel costs, etc.

Hence, practically from the very beginning of the existence of manned aerial vehicles, people tried to use, in parallel, unmanned aerial vehicles in different forms. That is why first the UAV systems date back to almost the same moment as those "manned ones". The $19^{\text {th }}$ century has been assumed to record one of the first applications of UAVs, when the Austrian army dropped bombs on the city of Venice just from such vehicles.

Also, at the end of the $19^{\text {th }}$ century, the UAV technique was utilized for photogrammetry-related purposes (Frenchman Arthur Batut and his photos taken from a kite).

We know it from our own experience, although the associations are not very positive as they concern World War II, when unmanned flying platforms carried

* AGH University of Science and Technology, Faculty of Mining Surveying and Environmental Engineering, Krakow, Poland

** University of Agriculture in Krakow, Poland

*** The paper has been prepared within the scope of the AGH statutory research no. 11.11 .150 .949 
explosive charges (unmanned V-1 and V-2 rockets). That technique was also used by American troops during their military operations in Vietnam (UAV Ryan 147 used to gather battlefield information). In fact, as statistics prove, the USA is the country definitely investing the most in that type of technology.

A wider development of UAVs for mapping purposes and first tests date back to the $1907 \mathrm{~s}$. In the beginning of the $21^{\text {st }}$ century practically the majority of countries that have something to say in photogrammetry already had scientific and research units that worked on that technology. The same can be said about Poland [4, 13].

The paper makes a certain summary of the existing state of knowledge worldwide, and indicates development tendencies in that field.

\section{Popularity of UAV Systems at Recent ISPRS Congresses}

The number of papers and reports published during the international congresses of the International Society of Photogrammetry and Remote Sensing (ISPRS) that are held every four years seems to be a good indicator of the growing popularity of UAV systems, and so, in 2004 (Istanbul), there were only three papers on UAV but in 2008 (Beijing) there were as many as 12 of them [15]. The 2012 congress (Melbourne) had 24 such reports [1, 3, 7, 10]. Also the mode of application, or the use of UAVs in various research fields, was being extended. Table 1 provides a list of the number of papers in relation to the particular Commissions of the ISPRS Congress. As the Table 1 shows, an increase in popularity of that measuring techniques is clearly visible, which means that the UAV technique is finding more and more applications [2, 9, 11, 12].

Table 1. Specification of the number of papers on UAVs during last three ISPRS congresses in relation to particular Commissions

\begin{tabular}{|c|c|c|c|}
\hline \multirow{2}{*}{ Commission } & \multicolumn{3}{|c|}{ Congress } \\
\cline { 2 - 4 } & $\begin{array}{c}\text { Istanbul } \\
2004\end{array}$ & $\begin{array}{c}\text { Beijing } \\
2008\end{array}$ & $\begin{array}{c}\text { Melbourne } \\
2012\end{array}$ \\
\hline \hline B-1 & 2 & 7 & 15 \\
\hline B-3 & - & 2 & 2 \\
\hline B-4 & - & - & 1 \\
\hline B-5 & - & 1 & 1 \\
\hline B-6 & - & - & 2 \\
\hline B-7 & - & - & 3 \\
\hline B-8 & - & 2 & - \\
\hline Forum & 1 & - & - \\
\hline Total & $\mathbf{3}$ & $\mathbf{1 2}$ & $\mathbf{2 4}$ \\
\hline
\end{tabular}


The majority of papers concerned descriptions of the construction and the use of UAV systems for various project related to geommetrisation or interpretation of image data $[4,6]$. Interesting is the fact that various UAV systems (nano-, micro-, mini-, or close- or medium-range UAVs), and sensors (from single cameras, through small-format camera sets, thermal cameras, multispectral cameras to hyperspectral cameras or laser scanners) are applied.

Part of the UAVs, considered to be the so-called "tactical vehicles", was classified in 2012 in accordance with the UAS Yearbook categories as shown in Table 2.

Table 2. Division of UAVs according to 2012 UAS Yearbook

\begin{tabular}{|c|c|c|c|c||}
\hline Category & $\begin{array}{c}\text { Range } \\
{[\mathrm{km}]}\end{array}$ & $\begin{array}{c}\text { Ceiling } \\
{[\mathrm{m}]}\end{array}$ & $\begin{array}{c}\text { Mission time } \\
{[\mathrm{hrs}]}\end{array}$ & $\begin{array}{c}\text { Maximum } \\
\text { take-off weight } \\
{[\mathrm{kg}]}\end{array}$ \\
\hline Nano-range & $<1$ & 100 & $<1$ & $<0.025$ \\
\hline Mikro-range & $<10$ & 250 & 1 & $<5$ \\
\hline Mini-range & $<10$ & $150-300$ & $<2$ & $<30(150)$ \\
\hline Close-range & $10-30$ & 3,000 & $2-4$ & 150 \\
\hline Short-range & $30-70$ & 3,000 & $3-6$ & 200 \\
\hline Medium-range & $70-200$ & 5,000 & $6-10$ & 1,250 \\
\hline Medium mission time & $>500$ & 8,000 & $10-18$ & 1,250 \\
\hline Low-ceiling & $>250$ & $50-9,000$ & $0.5-1$ & 350 \\
\hline Low-ceiling, long mission time & $>500$ & 3,000 & $>24$ & $<30$ \\
\hline Medium-ceiling, long mission time & $>500$ & 14,000 & $24-48$ & 1,500 \\
\hline
\end{tabular}

Source: [8]

In the case of equipment, there is an obvious tendency to minimize sensors (since weight matters). The dominating cameras include such, as IGI DigiCAM (60 Mpx, Pentax Optio A 40 (12 Mpx), or Canon 5D or 550D (18 Mpx).

The chief application of UAVs is that related to photogrammetry. An example of a typical project involving UAVs was the execution of aerial triangulation for the city of Shanxi from 1,024 photos made with Canon 5D camera (5616 $\times 3744$ pixels), yielding the accuracy of $0.2 \mathrm{~m}$ after $X, Y$ and $0.35 \mathrm{~m}$ after $Z$, at $10-\mathrm{cm}$ pixels, which is a considerably good result (the project goal was mapping at a scale of $1: 1,000)$ [7].

An untypical example was that of a project, which employed a mini-UAV system, named MK-Okto (HiSystems $\mathrm{GmbH}$ ), furnished with a NEC F30 IS camera. The project concerned making photos with thermal and multispectral cameras. The goal of the project was to assess impurities in sugar beet crops with the use of noninvasive measuring methods. The flight altitude was $55 \mathrm{~m}$ above the ground level in transparent air conditions. The vehicle recorded thermal images, $120 \times 160$ pixels, 
and multispectral images, 1,280 × 1,024 pixels. The field pixel size was $17 \mathrm{~cm}$ and $1.4 \mathrm{~cm}$ for multispectral images. The accuracy of GPS positioning was on the level of $1 \mathrm{~cm}$, which is satisfactory for UAV systems [3].

Another interesting application is the use of an UAV to make surveys and perform a 3D modelling of a Buddhist fortress Drapham Dzong Bhutan, where the ready UAV md4-200 quadrocopter was used, with the GPS system and a Panasonic Lumix FX35 camera (the "md4-200" is a product of Microdrones, today model "md4-1000" is available) [5].

UAVs were also used to explore the basin of Antarctica. A 6-channel, multispectral camera was used, installed on a microcopter. The camera was a Tetracam mini-MCA, able to record six images $(1,280 \times 1,024$ pixels $)$ at the same time in a continuous way, in 530, 550, 580, 670, 700, and $800 \mathrm{~nm}$ bands [10].

\section{UAVs in Poland}

Constructing the UAV system in Poland has also its history. In 2007 Dr. Bogdan Jankowicz (presently the University of Agriculture in Krakow, Poland) conducted research on an unmanned motor hang-glider, furnished with a Vivitar camera. The results of his research were presented in his postdoctoral thesis. Research works were also conducted by Mr. Bogdan Szczechowski from the Gdańsk University of Technology, Poland, in cooperation with Microsystems Company [14]. The research outcomes included developing a technology of producing orthophotomaps from a drone and, finally, implementing several practical projects.

Also at the Warsaw University of Life Sciences, a Ph.D. student Anna Zmarz defended her doctoral thesis, where she utilized the UAV technique to make images and to analyse the condition of forests.

The technology of unmanned systems has also found commercial applications. Several Polish companies, such as Opegieka from Elblag, Eurosystem from Chorzów, Taxus SI from Warsaw, or Fotomapy from Grodzisk Dolny have invested in that technology. The last of those companies developed its own solution (the "Pteryx" drone). This vehicle can make up to $10 \mathrm{~km}^{2}$ of a map during a single flight.

Taxus SI for more than two years have been building their own UAV, named AVI-1, exhibited later at the INTERGEO fair in 2011.

A separate issue is that of legal regulations. In the case of unmanned flights, these are the system parameters that have quite an essential importance: if the aerial vehicle weights more than $30 \mathrm{~kg}$, its operator must hold a special license and a permit to make such flights. However, in the case of smaller devices, the permit is theoretically required but, at the same time, one can treat the device and its flight as an aircraft modelling hobby. Then, if the drone remains within one's view (flight altitude not exceeding $150 \mathrm{~m}$ and at least $150 \mathrm{~m}$ from urban areas) it can be used. 


\section{Attempts at Constructing an UAV at the AGH University of Science and Technology in Kraków, Poland}

A few years ago Dr. Grzegorz Chmaj from the Institute of Mechatronics at the Faculty of Mechanical Engineering and Robotics, AGH University of Science and Technology in Krakow, Poland constructed a model of a mini-helicopter named "Aquila" that was able to carry a load of up to $10 \mathrm{~kg}$. The vehicle head can be furnished with a small photo camera, a camera (e.g. thermal one), or a LiDAR. The effect of research works was the establishing of a company UAVS Poland Sp. z o.o. (Fig. 1), with the University and the helicopter authors as the Company partners.

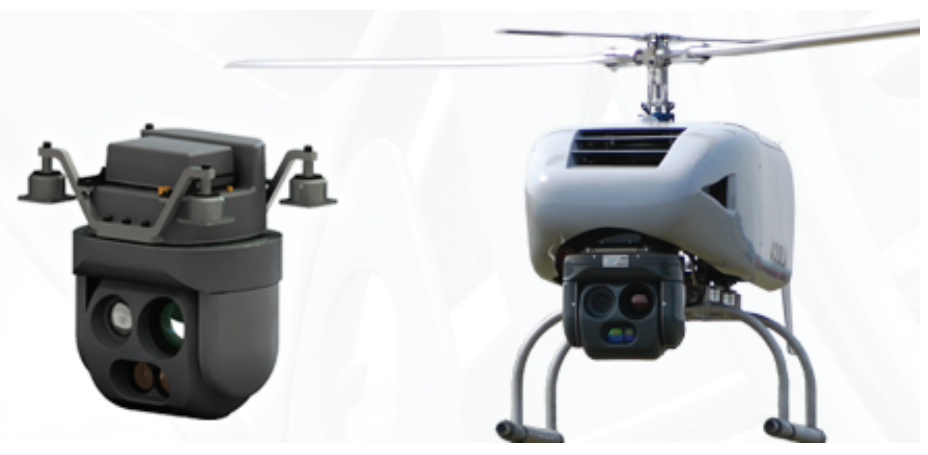

Fig. 1. Target Tracking System with Aquila

For several years, scientists from the Department of Geoinformation, Photogrammetry and Remote Sensing have been conducting research mainly on the calibration of non-metric cameras and the use of other measuring equipment that can be applied in the UAV technology (thermal cameras, hyperspectral cameras, laser scanners). Presently, in cooperation with one of Krakow-based companies, a model of a quadrocopter has been constructed for the low-ceiling acquisition of data (Figs 2, 3). The project is at the implementation phase.

The constructed multirotor (or colloquially a helicopter) shall meet the following assumptions:

- control system based on real-time broadcasting of video images from the vehicle to the control centre, the so-called "Field Base"; that type of control is effected in such a way so that a person controlling the drone could fully control it, while having the whole spectrum of flight parameters "imposed" on "the view from the pilot's cabin"; images from the aerial vehicle shall be displayed by means of special goggles on the operator's (the "pilot's") head, who will have a view from the camera on the vehicle; additionally, flight and vehicle parameters shall be integrated with images; 
- take-off weight not to exceed $5 \mathrm{~kg}$;

- operation time minimum 15 minutes, depending on the weight of additional photogrammetric equipment;

- in emergency situations, the automatic system of the aerial vehicle will enable its autonomous flight back to the base, and in unfavourable conditions it shall enable the autonomous landing and transmitting of a special signal to identify the aircraft location;

- navigation equipment shall include a precise altimeter connected to the GPS receiver and a telemetric system to ensure a two-directional communication: the base-vehicle;

- the vehicle shall be driven and its equipment supplied from highly-efficient lithium-polymer cells linked to inverters, and the inverters generating a threephase current shall control the motors; the central unit of the vehicle shall be furnished with a micro-controller, to which data from the GPS receiver, altitimeter, compass, acceleration detectors/gyroscopes shall be transmitted;

- flight parameters and images from the aerial vehicle shall be recorded (by the so-called black box); this, in case of any technical problems, will allow performing analyses necessary to solve those problems and will considerably accelerate the project completion, thus reducing the related costs;

- additional equipment to accomplish project assumptions shall include photogrammetric equipment, allowing for an internal release of shutter and recording projection centres by means of the GPS receiver; Also the use of various-type cameras has been intended: night-vision cameras, thermal cameras, as well as a multi-spectral one;

- there shall be an independent work station in the "Field Base" for the operator of photogrammetric and telemetric systems to enable the display of data from the vehicle necessary for the task involving the acquisition of materials to be further processed for the fabrication of a ready product; the operator at that work station shall be able to monitor the video image from the camera so that to get the required material, without the necessity for "replays".

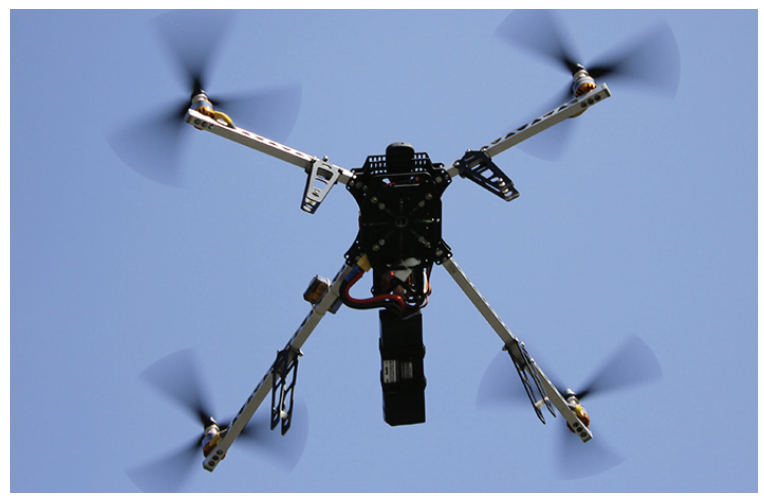

Fig. 2. The AGH UST multirotor (phot. Mikrut, Skalny) 


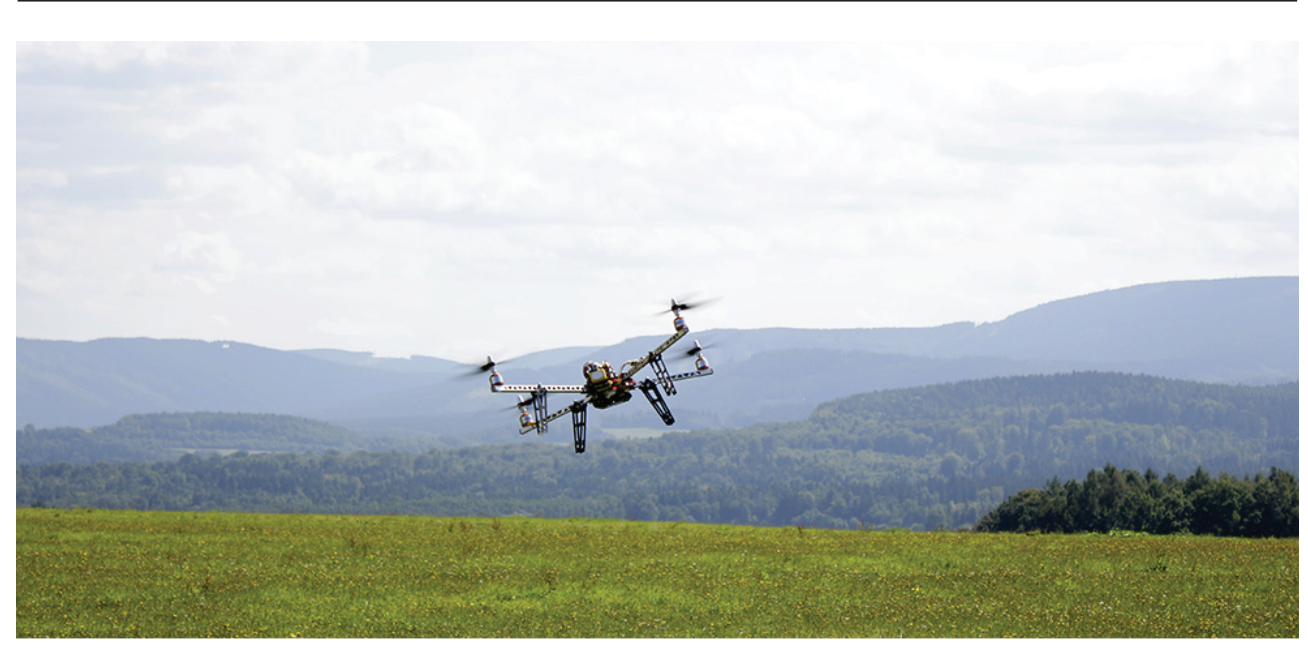

Fig. 3. The AGH UST multirotor in operation (phot. Mikrut, Skalny)

The first tests that have been made confirm the stability of positioning, as proved by the quality and sharpness of the images.

\section{Summary}

The goal of this paper was to review the current state of knowledge concerning the UAV technology, both in the world, and in Poland. More than 30 papers and reports were reviewed and analysed, with their contents including examples of the worldwide utilization of UAVs. The explicit conclusion is that the UAV technology keeps developing year after year, more and more rapidly, and that more and more interesting projects are being implemented, both scientific, and commercial ones. It results from the materials reviewed that the main application of UAVs is the pointwise acquisition of image data for various purposes (maps, terrain models, thermal images). Attempts at obtaining data by means of other sensors are also made (laser scanners, infrared cameras, and hyper-spectral cameras). The first projects have already been completed. One should therefore assume that the UAV technology will continue to develop in a very dynamic way. At this moment it surely has its limitations, to mention only legal regulations, referenced in Section 4, which in Poland are quite restrictive. Another limitation is the small weight of those flying vehicles, which on the one hand is an advantage (low operating costs), but on the other is a disadvantage (difficulties with maintaining flight stability, which limits the data registration capabilities because of weather conditions).

There are two main trends visible in the development of drones:

1) small and light multi-rotors (for very small projects),

2) bigger and heavier vehicles (for making images on a bigger scale). 
As regards to the installation of sensors aboard of UAVs, the range of devices is wide. Classic non-metric cameras are more and more often replaced with cameras of continuous recording. A future-oriented development tendency is the installation of laser scanners and hyperspectral sensors (e.g. Rikola Hyperspectral UAV camera can record 50 spectral channels within 500-950 nm range). UAVs implement projects in the fields of typical photogrammetry (mapping), teledetection, or the so-called precise agriculture.

A new and interestingly developing field is the opening of the possibilities of controlling UAV systems by means of smartphones or other electronic devices, such as iPods or iPads.

Summing up, one can say that originally the objective of developing the UAV technology was the reduction of the cost of data acquisition from the airborne ceiling. Today we can confidently declare that part of that has been achieved. The already emerging first products of that technology implementation are successfully utilized in selected projects.

\section{References}

[1] Anai T., Sasaki T., Osaragi K., Yamada M., Otomo F., Otani H.: Automatic exterior orientation procedure for low-cost UAV photogrammetry using video image tracking technique and GPS information. The International Archives of the Photogrammetry, Remote Sensing and Spatial Information Sciences, vol. XXXIX-B7, 2012, pp. 469-474.

[2] Bakuła K., Ostrowski W.: Zastosowanie cyfrowej kamery niemetrycznej w fotogrametrii lotniczej na wybranych przykładach. Archiwum Fotogrametrii, Kartografii i Teledetekcji, vol. 24, 2012, pp. 11-20.

[3] BendigJ., Bolten A., Bareth G.: Introducing a low-costmini-UAV for thermal-and multispectral-imaging. The International Archives of the Photogrammetry, Remote Sensing and Spatial Information Sciences, vol. XXXIX-B1, 2012, pp. 345-349.

[4] Eisenbeiss H.: A mini Unmanned Aerial Vehicle (UAV): system overview and image acquisition. The International Archives of Photogrammetry, Remote Sensing and Spatial Information Sciences, vol. XXXVI-5/W1, 2004 [on CD-ROM].

[5] Gruen A., Zhang Z.: Eisenbeiss H.: UAV Photogrammetry in Remote Areas - 3d Modeling of Drapham Dzong Bhutan. The International Archives of Photogrammetry, Remote Sensing and Spatial Information Sciences, vol. XXXIX-B1, 2012, pp. 375-379.

[6] Haala N., Cramer M., Weimer F., Trittler M.: Performance test on UAVbased photogrammetric data collection. The International Archives of the Photogrammetry, Remote Sensing and Spatial Information Sciences, vol. XXXVIII-1/C22, 2011, pp. 7-12. 
[7] Junqing Ch., Zongjianb L., Xiaojinga W., Yongrong L.: Application of UAV system for low altitude photogrammetry in Shanxi. The International Archives of the Photogrammetry, Remote Sensing and Spatial Information Sciences, vol. XXXIX-B1, 2012, pp. 351-354.

[8] Królikowski J.: Latać każdy może. Magazyn Geoinformacyjny - Geodeta, nr 7, 2011, pp. 48-51.

[9] Laliberte A., Herrick J., Rango A., Winters C.: Acquisition, orthorectification, and object-based classification of unmanned aerial vehicle (UAV) imagery for rangeland monitoring. Photogrammetric Engineering and Remote Sensing, vol. 76(6), 2010, pp. 661-672.

[10] Lucieer A., Robinson S., Turner D., Harwin S., Kelcey J.: Using a microUAV for ultra-high resolution multi-sensor observations of Antarctic moss beds. The International Archives of the Photogrammetry, Remote Sensing and Spatial Information Sciences, vol. XXXIX-B1, 2012, pp. 429-433.

[11] Nebiker S., Annen A., Scherrer M., Oesch D.: A light-weight multispectral sensor for micro UAV - opportunities for very high resolution airborne remote sensing. The International Archives of the Photogrammetry, Remote Sensing and Spatial Information Sciences, vol. XXXVII, 2008, pp. 1193-1200.

[12] Remondino F., Barazzetti L., Nex F., Scaioni M., Sarazzi D.: UAV photogrammetry for mapping and $3 d$ modeling - current status and future perspectives. The International Archives of the Photogrammetry, Remote Sensing and Spatial Information Sciences, vol. XXXVIII-1/C22, 2011, pp. 25-31.

[13] Sawicki P.: 2012. Bezzałogowe aparaty latajace UAV w fotogrametrii $i$ teledetekcji - stan obecny i kierunki rozwoju. Archiwum Fotogrametrii, Kartografii i Teledetekcji, vol. 23, pp. 365-376.

[14] Szczechowski B.: Wykorzystane bezzałogowych aparatów latajacych (mini śmigłowców) do wykonywania fotogrametrycznych zdjęć lotniczych z niskich putapów. Archiwum Fotogrametrii, Kartografii i Teledetekcji, vol. 18, 2008, pp. 365-376.

[15] Zongiian, L.: UAV for mapping-low altitude photogrammetric survey. The International Archives of Photogrammetry and Remote Sensing, vol. XXXVII-B1, 2008, pp. 1183-1186. 